\title{
SAMUEL BECKETT, EL INNOMBRABLE Y EL FIN DE LA MODERNIDAD
}

\author{
FERNANDO DE TORO \\ Universidad de Manitoba \\ Department of English, Film, and Theatre \\ Winnipeg, Manitoba, Canada R3M 3H8 \\ fdetoro@cc.umanitoba.ca
}

\section{RESUMEN:}

Nuestro interés en este estudio sobre El Innombrable de Samuel Beckett es efectuar una lectura sobre el contexto cultural y critico de este texto a fin de especificar la posición de Beckett frente a la Modernidad y la posición de la crítica con respecto a El Innombrable. Luego procederemos a un análisis detallado del texto a partir de tres ejes fundamentales: a) Beckett y la escritura rizomática: el fin de la estructura narrativa, b) Beckett y el fin de la representación, c) Beckett y la problemática del Sujeto. Esperamos que este acercamiento proporcionará una lectura distinta de $E l$ Innombrable.

Palabras Clave. Sujeto. Rhizoma, Sujeto, Modernidad. Representación. Lenguaje.

\section{ABSTRACT:}

Our interest in this study of The Unnamable by Samuel Beckett consists in a reading pertaining the cultural and critical context of this text with the objective to specify Beckett's position vis-à-vis Modernity and the critics' position with respect to The Unnamable. Then, we will proceed to a detailed analysis of the text from three fundamental perspectives: a) Beckett and rhizomatic writing, b) Beckett and the end of representation, c) Beckett and the problematic of the Subject. We hope that this approach will provide a different reading of The Unnamable. 
KEY WorDs: Rhizome. Subject. Modernity. Representation. Language.

Die Sprache allein ist es, die eigentlich spricht. Und sie spricht aunsam. Martin Heidegger, Unterwegs zur Sprache.

\section{¿POR DÓNDE COMENZAR?}

Escribir sobre la 'narrativa' de Samuel Beckett es, para mí un acto irreverente, puesto que es una obra extremamente compleja y de una dificilísima lectura. Es, a mi ver, el narrador más complejo de toda la literatura occidental. Irreverente, puesto que intentar una 'explicación', no digo ya una interpretación, es correr el riesgo de imponerle a sus textos una lectura, que por más inteligente y sutil que sea, es externa a ellos, esto es, procede de la urgencia de desentrañar 'algo' de lo que el texto 'intenta' decir en vez de dejar que el texto hable por sí solo. ${ }^{1}$

Por mi parte deseo dejar que el texto(s) me hable(en), esto es, hacer una lectura hermenéutica en el sentido filosófico de esta actividad, una lectura intima, cercana, siguiendo la práctica de lectura que Derrida nos enseñó.

Sin embargo, antes de iniciar la lectura de El innombrable, me es imprescindible situar claramente mi posición de lectura ante los textos de Beckett y particularmente con respecto de El innombrable que es el texto que aquí nos ocupa.

Mi interés por la escritura de Beckett se encuadra en una investigación más amplia, la cual tiene que hacer con el fin de la Modernidad y el lugar que en este fin ocupa Beckett. Así, para poder seguir mi lectura de El innombrable, es preciso que sitúe a Beckett con respecto a las siguientes reflexiones; primero en un contexto cultural y crítico y luego en un acercamiento reflexivo de El Innombrable. Con respecto al primero, reflexionaremos sobre Beckett y su relación con la Modernidad y sobre algunos aspectos centrales sobre la producción crítica de la obra de Beckett. Luego procederemos a una reflexión sobre El Innombrable a partir de los siguientes puntos: a) Beckett y la escritura rizomática: el fin de la estructura narrativa, b) Beckett y el fin de la representación, c) Beckett y la problemática del Sujeto.

\section{CONTEXTO CULTURAL Y CRÍTICO}

En esta sección nos centraremos en dos aspectos que consideramos centrales para situar a Beckett en un lugar donde nuestra lectura pueda ser productiva: a) Beckett y la Modernidad y b) Beckett y la crítica. Mucho se ha escrito sobre si Beckett es o no es un escritor perteneciente a la Modernidad o a la Post-Modernidad avant la lettre. Por ello es necesario establecer mi posición en este debate que sin duda ha creado y continúa creando una gran confusión con respecto a este punto. Similar es lo que sucede con la crí-

\footnotetext{
${ }^{1} \mathrm{Y}$ esto es exactamente lo que ha sucedido con la vastísima crítica que se ha producido sobre Beckett, como lo indicaremos en la sección «Beckett y la crítica» de este estudio. Ver también el libro de Pascale Casanova,

Beckett l'abstracteur. Anatomie d'un révolution littéraire (1997).
} 
tica, donde encontramos tantas interpretaciones como hay críticos. Por ello también es preciso que introduzca claramente mi forma de encarar a Beckett, la cual sin duda determina la totalidad de mi pensamiento con respecto a su obra y a mi lectura de El Innombrable.

\section{BECKETT Y LA MODERNIDAD}

En la extensa bibliografía sobre la obra de Beckett éste es situado o bien como un escritor de la Alta Modernidad o bien como un escritor Post-Moderno avant la lettre. Mis investigaciones sobre esta problemática, como la hemos establecido en «Borges, Lispector, Rulfo, Gaudí, Beckett, Kandisnky, Ginsberg, Schoenberg, Kafka, Duchamp, Mondrian, Cage, Stockhausen, Pollock y Warhol: El fin de la Modernidad» (2010), demuestra que Beckett nunca participó de la estética narrativa de la Modernidad literaria iniciada por James Joyce. El sólo hecho que en un nivel temporal esté situado dentro de la Modernidad no implica para nada que haya participado en aqué1la. Pienso que la crítica no ha considerado esta posibilidad, que de hecho vendría a explicar de una forma substancial por qué Beckett introduce una escritura sin precedentes y, de cierta forma, sin seguidores. ${ }^{2}$ El hecho mismo de considerarlo como un escritor de la Modernidad o de la Post-Modernidad señala la confusión y la extrañeza de la crítica frente a la escritura beckettiana.

Pascale Casanova en su libro Beckett l'abstracteur: anatomie d'une révolution littéraire (1997) señala:

Contraint d'écrire après Joyce et, pour ne pas l'imiter, au-delà de lui, Beckett s'engage sur la voie d'une autre modernité formelle. L'abstraction littéraire qu'il invente, au prix de l'immense travail de toute une vie, pour mettre la littérature à la hauteur de toutes les grandes révolutions artistiques du siècle - et en particulier de l'abstraction picturale - va reposer sur une combinatoire littéraire inédite. (1997: 9)

Pascale Casanova comete aquí dos errores fundamentales: primero, pensar que Beckett se aparta de Joyce para crear una Modernidad diferente! Beckett comienza a publicar a fines de los años $1930^{3}$ (Murphy en 1938) y la trilogía, fundamental en el proyecto beckettiano, publicada entre 1951-1953, (Molloy en 1951, Malone muere en 1951 y El innombrable en 1953), esto es, cuando la Modernidad ya había concluido, no es posible concebir que Beckett se embarcara en la introducción de una Modernidad diferente. El problema estriba aquí en qué temporalidad y noción de Modernidad está empleando Casanova y esto es algo que ella no establece en su libro.

Por nuestra parte consideramos que la Modernidad se inicia hacia fines del siglo XIX, alrededor de los años 1896 y termina con la inserción de nuevos paradigmas (Kuhn, 1979) para 1925 y continua como ciencia normal (Kuhn, 1970) clausurándose la

\footnotetext{
${ }^{2}$ Digo 'de una cierta forma' puesto que en mi opinión su escritura tendrá un efecto fundamental en la literatura femenina tal cual la encontramos en Clarice Lispector, Cathy Acker o Hélène Cixous.

${ }^{3}$ Una excepción es Dream of Fair to Meddling Women, escrita en 1932 pero publicada en 1992.
} 
Modernidad para mediados de los años 1950. Es esta realidad, y esta es nuestra tesis, y el establecimiento de la Modernidad narrativa por James Joyce, que conduce a Beckett a una reflexión muy similar a la de Borges, esto es, a no seguir el modelo establecido por Joyce. En esto Casanova tiene razón, pero este apartarse de Joyce no fue para crear una nueva Modernidad sino para liquidarla. Mientras Borges logra el Übervindung (Vattimo, 1985), esto es, el sobre pasar la Modernidad y evitarla completamente, ${ }^{4}$ Beckett no logra el Übervindung, sino que se embarca en la deconstrucción de la Modernidad: después de Beckett no habrá más narrativa Moderna y se tendrá que comenzar a escribir de una forma diferente y esta forma es la que se ha llamado literatura post-moderna. Es a través de la forma y del lenguaje que Beckett logrará dar fin a la Modernidad literaria como veremos más adelante en este estudio.

El otro error en la cita de Casanova, es que ella asocia la abstracción de Beckett a la pintura Moderna (Picasso et al? ver Casanova, 1997: 128) y a la liquidación del sentido. Pero esta abstracción y liquidación del sentido está asociada, a mi ver, no a la pintura moderna sino al 'Pop Art' que se inicia con artistas como Marcel Duchamp y Piet Mondrian a comienzo del silgo XX, quienes tampoco fueron parte de la Modernidad pictórica establecida por los ismos del primer tercio del siglo XX (De Toro, 2010). Casanova señala que Beckett con su escritura quería poner la literatura a la par con la pintura Moderna del siglo XX, pero olvida que el siglo XX tiene dos paradigmas distintos, la Modernidad (1889-1955) y la Post-Modernidad (1960-2000). Además el abstraccionismo en literatura está presente desde James Joyce, así no comprendo por qué, lo cual es un error, Beckett tendría que introducir la abstracción como algo no dado, como algo 'nuevo'.

Lo que está en juego aquí es la noción de representación, que según Casanova los escritores modernos no habían cambiado radicalmente, en particular, los novelistas. Sostener que narradores como James Joyce, Franz Kafka, Herman Broch, Robert Musil, etc., no desafían la representación, es simplemente no saber de qué se está hablando. ${ }^{5}$ La novela, como el teatro de ese período, salvo algunas excepciones, está marcada por la abstracción (1997: 10). Lo que sí realiza Beckett es el implotar la novela moderna eliminando el sentido e introduciendo un nuevo tipo de estructura: la estructura rizomática. No deja ningún vestigio de la novela moderna y conduce la literatura de la Modernidad a su inevitable fin. Beckett se sitúa en la transición de la Modernidad a la Post-Modernidad y es este el espacio de trabajo de Beckett y el cual estoy investigando.

Jean Valenti señala al respecto que desea mostrar

[...] que l'opus beckettienne n'est ni humaniste ni déconstructiviste avant la lettre, mais qu'il repose sur une esthétique de l'entre-deux, du va-et-vient entre un système de références existentialo-humaniste et une tentative de mise en crise du sens. (2006: 203)

Lo que interesa de esta afirmación de Valenti es que señala la pertinencia de no situar a Beckett dentro de la Modernidad o de la Post-modernidad, insistiendo en ese espacio li-

\footnotetext{
${ }^{4}$ Véase al respecto nuestro estudio «Borges y Rulfo: los paradigmas de la Modernidad y de la Post-Modernidad (2002).

${ }^{5}$ La problemática de la novela moderna ha sido detalladamente estudiada por Wladimir Krysinski en La novela y sus modernidades (1998).
} 
minal, entre-medio del cual vengo hablando. En esto, Valenti es el único, aunque de una perspectiva diferente a la nuestra, en indicar la importancia de este espacio entre-medio. Con respecto a esta problemática Richard Begam sostiene que:

It will be my claim that these novels [Murphy, Watt, Molloy, Malone Dies, and The Unnamable] provide the earliest and most influential literary expression we have of the «end of modernity». (1996: 3)

Estoy en total acuerdo que estos textos de Beckett (como todos los de su obra narrativa y teatral) son sin duda claves puesto que llevan al fin de la Modernidad, sin embargo Begam nunca explica en qué consiste el fin de la Modernidad. Como Begam pienso que Beckett solamente puede ser leído de una forma productiva a través del Post-Estructuralismo (Begam, 1996: 3) como quedará claro en este estudio. Begam también tiene razón que muchos de los temas que confrontará el Post-Estructuralismo ya estaban presentes en Beckett (escritura rizomática, el sentido diferido y la problemática del Sujeto), como más de una década anterior, estaban presentes en Borges. Sin embargo, el hecho que existan problemáticas post-estructuralistas en la obra de Beckett, para nada lo hace un escritor post-moderno. Esta es una diferencia fundamental que no puede ser ignorada. Beckett anula el sentido y el narrador astilla un relato que no relata nada sino el enunciado/enunciación de una voz, y este no es el caso de la literatura post-moderna introducida por Borges en Ficciones ([1941] 1956) y continuada por Augusto Roa Bastos con Yo el Supremo (1974), obra que a mi ver inaugura la Post-Modernidad literaria internacional. La intertextualidad y la doble codificación (Jencks, 1989), como la escritura palismpséstica y el 'relato' como simulación, son parte integrante de la literatura post-moderna y estos elementos no están presentes en Beckett. No se puede confundir, como se ha hecho (David Weisberg, 2000) la intratextualidad de los textos de Beckett con la intertextualidad postmoderna puesto que son dos cosas distintas. El hecho que Beckett cite, por ejemplo, personajes de sus otros textos o de la trilogía en El Innombrable, no tiene nada que hacer, a mi ver, con intertextualidad, sino con el proyecto beckettiano de instalar al Otro y llevar el lenguaje, la narración y el narrador a su fin y, que en efecto, no logra, como se ha sostenido insistentemente, con El Innombrable, sino con Worstward Ho. Begam coincide con mi propuesta que Beckett escribe en un espacio liminal, transitorio al afirmar que: «Acknowledging that an absolute transcendence of modernism is impossible, Beckett turns to exploring the différential space that lies between modernism and antimodernism» (1996: 7). La razón por la cual «an absolute transcendence of modernism is impossible» se debe a que Beckett no sobrepasó la Modernidad, como Borges que da inicio a la Post-Modernidad literaria, sino que la concluyó. Luego, la Post-Modernidad no es anti-moderno, como sugiere Begam (1996: 7).

Otro problema que plantea el estudio de Begam es con respecto de qué fin de la Modernidad se trata, puesto que parecería que su noción Modernidad está vinculada al Siglo de las Luces, y en esto sigue a Habermas quien sostiene al respecto,

The project of modernity formulated in the 18th Century by the philosophers of the Enlightenment consisted in their efforts to develop objective science, universal morality and law, and autonomous ar according to the inner logic. (1998: 8) 
Según Begam, «The idea of the Enlightenment traditions has placed itself out, that modernity has come to an end, is most often identified with Lyotrard's celebrated exchange with Habermas» (1996: 13). Si esta es su noción de Modernidad entonces estamos hablando de distintas cosas. Según Begam, el fin de la Modernidad se establece con las diversas posturas desde Nietzsche, pasando por Heidegger y luego por Foucault, Derrida, Lyotard, Rorty y Vattimo (1966: 13). Así, para éstos «[...] modernity has come to an end precisely to the extent that the «philosophy of the subject» has come to an end (1966: 13). Por mi parte tomo una ruta diferente, puesto que la Modernidad no terminó simplemente porque la filosofía del Sujeto concluyó. Esto es sin duda un elemento, pero no el elemento definitorio, pero si un elemento central en cuanto a la filosofía.

Además, y por sobre la problemática del Sujeto, los Post-Estructuralistas sin duda derribaron el edifico Formalista que se inicia a principios del siglo XX, incluyendo la metafísica, y que concluye con la semiótica estructural hacia fines de los años 1960 - mediados de los 1970. Sin embargo, en las artes y la literatura esta liquidación del formalismo y de la Modernidad se realiza antes (años 1950) del desmantelamiento teórico-filosófico que Post-Estructuralismo iba a efectuar desde fines de los años 1960.

Lo fundamental para mí es tratar los textos de Beckett como escritura, una escritura sin precedentes y de intentar responder a la pregunta ineludible: ¿por qué surge este tipo de escritura? La Modernidad concluye, no solamente desde la filosofía, sino también desde el campo cultural en general, incluyendo la literatura, y Beckett en esto es un ejemplo sin igual.

Otro estudio significativo, sobre el tema que nos ocupa, es el de David Weisberg, $C h$ ronicles of Disorder: Samuel Beckett and the Cultural Politics of the Modern Novel (2000). Allí señala que Beckett no participó de la Modernidad literaria como tampoco de la política cultural del momento, puesto que

[...] Beckett crystallized his conflicted experience of the 1930s' culture Wars in a series of fictions - written between 1945 and 1950 - that compulsively challenged the assumptions and values of modernism, cultural vanguardism, and social commitment in relation to one other. (2000: 2)

Weisberg adopta una posición muy diferente con respecto a la supuesta Post-Modernidad de Beckett la cual rechaza de plano (2000: 2) y tiene razón puesto que sería un error considerar a Beckett como un escritor post-moderno, sin embargo no explica por qué. Pienso que aquí hay dos confusiones: a) el Post-Estructuralismo no es algo separado de la Post-Modernidad y esto es una confusión extendida en los estudios sobre la PostModernidad. Desde nuestro punto de vista, el Post-Estructuralismo, repito, es parte integral de la Post-Modernidad proporcionándole las fundaciones epistemológicas a aquélla. Por otra parte, nada estoy de acuerdo con Andreas Huyssen (1984: 45) quien sostiene que el Post-Estructuralismo es una teoría de la Modernidad, pero en efecto es una crítica de todo el pensamiento Occidental donde la Modernidad fue el punto de llegada catastrófico; b) el hecho que en Beckett existan problemáticas que luego serán teorizadas por el Post-Estructuralismo y que serán centrales en los textos literarios de la Post-Modernidad, tales como el diferimiento del sentido, la desaparición del narrador reemplazado por la escritura (Barthes, 1967), la escritura sin referente (autotélica) o la fragmen- 
tación del Sujeto, no hace a Beckett un escritor post-moderno. Weinsberg es categórico en su rechazo de la Post-Modernidad beckettiana y de su vinculación y lectura postestructuralista de los críticos (2000: 5). El problema con la posición de Weinsberg es que no explicita dónde se sitúa Beckett. Por una parte, critica a la crítica que lo sitúa en la Alta Modernidad y, por otra, la que lo sitúa en la Post-Modernidad, que él llama vanguardia, sugiriendo que esto es anacrónico. Admite, a su vez, que Beckett lleva a su límite la Modernidad narrativa, pero no explica cómo lleva la Modernidad a su límite. Si Beckett no entra en la Modernidad, con lo cual concordamos, y tampoco es parte de la Modernidad, entonces ¿dónde si sitúa según Weinsberg? Por mi parte lo sitúo en un espacio transicional, esto es, en un espacio donde Beckett concluye la Modernidad pero no la supera en el sentido de crear una nueva ciencia normal (Kuhn, 1970) esto es, introduce un nuevo paradigma (Kuhn, 1970) que se disuelve a sí mismo.

Finalmente, el estudio de Anthony Uhlmann, Becket and Poststructuralism es uno de estos casos donde se realiza un análisis de Beckett desde la filosofía, estableciendo relaciones entre aquélla y los textos de Beckett y las posibles lecturas filosóficas de éste. El problema con este estudio reside en su carácter especulativo y en que jamás entra realmente en los textos, excepto para subrayar coincidencias de tipo filosófico. En la «Introducción» señala:

In general terms this book will seek to situate Molloy, Malone Dies, and The Unnamable within a French intellectual and historical milieu: specifically by relating these works to concepts and ways of seeing developed by French, poststructuralist so as to shed light on Beckett's novels. (1999:3)

[...]

I am interested in the Beckett who is loosely described as a 'philosophical' writer. (1999: 3)

Hay dos problemas en estos comentarios; por una parte, si se trata de situar a Beckett en su 'medio intelectual e histórico' este tendría que ser entre los años 1930 y 1950 y no dentro del Post-Estructuralismo que no arranca de hecho sino hasta los años 1970 aunque muchas obras seminales se comienzan a escribir desde fines de los años 1960; por otra parte, encuentro cuestionable el caracterizar su obra como filosófica, puesto que si este hubiera sido su propósito, entonces habría escrito filosofía y no 'literatura'. Mi postura frente a temas filosóficos (o psicoanalíticos) en Beckett es muy distinta a la de Uhlmann: situar a Beckett en el contexto intelectual y teórico del Post-Estructuralismo me parece un error, puesto que la producción literaria de Beckett se adelanta por mucho a pos-estructuralistas tales como Derrida, Deleuze, Guattari, Baudrillard o Foucault. Lo que si sucede es que Beckett ante una Modernidad literaria instalada desde fines del siglo XIX lo conduce no a seguirla sino a obliterarla. Para ello se vale de todos los elementos que constituían la Modernidad literaria o los conduce a su límite, a su implosión. La Modernidad literaria fragmenta la estructura narrativa y la voz narrativa se inscribe en el flujo de la conciencia y esta voz es constituida siempre en un narrador identificable, y en un espacio y tiempo, aunque fragmentados, también describibles. Son estos elementos los que Beckett lleva a su límite, como quedará claro en nuestro análisis de El Innombrable. Los procedimientos de los cuales se vale serán teorizados e introducidos por los post-estructuralistas a partir de fines de los años 1970 y esto permite establecer un diálogo con al 
obra de Beckett y los post-estructuralistas. Desde nuestro punto de vista, Beckett no podía ser leído de una forma productiva y que no distorsionara su obra hasta que esos procedimientos, que Beckett introduce, pudieran ser descritos y teorizados. Lo que nos proporciona el Post-Estructuralismo es precisamente una forma productiva de leer a Beckett, una lectura que procede desde su escritura y de las problemáticas que trata y no de algo exterior que se le impone a esa escritura.

Anthony Uhlmann propone un acercamiento 'anti-platonista' a Beckett y señala precisamente la crítica que aquí le hago:

[...] I will hope to show throughout the book as a whole that the new situations confronted by Beckett on an aesthetic plane constituted urgent questions which confronted a whole generation of thinkers across different disciplines; further, that they thereby required a new philosophical approach (one which, and I will define this term more precisely below, might be termed 'anti-Platonic) in order to be understood conceptually and that this approach emerges clearly in the works of Foucault, Deleuze and Guattari and Derrida. (1999: 5)

He citado este pasaje para claramente demarcar la posición de Uhlmann con respecto a los post-estructuralistas y la mía. Este pasaje merece algunos comentarios puntuales. En primer lugar, Uhlmann sostiene que Beckett y los post-estructuralistas proceden de una tradición intelectual común y cuando establece estos vínculos éstos proceden de una interrelación de lecturas (compartidas) en vez de fijarse en los textos de Beckett, como textos. ${ }^{6}$ No sé cuál es el aporte que un tipo de estudio semejante pude hacer para 'comprender' la obra de Beckett. A mi ver, lo que sí comparte Beckett con los post-estructuralistas es su postura vis-à-vis la Modernidad. Mientras Beckett oblitera la narrativa moderna a través de una serie procedimientos (indicados más arriba), los postestructuralistas se encargaron de derribar todo el edificio formal establecido desde los Formalistas Rusos en adelante (de Toro, 2007): lo que comparten es la liquidación de la Modernidad en todos sus aspectos centrales. De la misma forma que la escritura y los textos Beckett cancelan toda una larga tradición narrativa occidental, dejando sólo astillas de la misma, los post-estructuralistas cancelaron para siempre toda pretensión cientifista del formalismo extremo. Estoy de acuerdo que Beckett pensó diferentemente, pero no por que se asocie su pensamiento a otros afines, sino que lo que pensó diferentemente fue la Modernidad narrativa. Ante una Modernidad que ya había concluido para cuando el comienza a escribir, ¿qué recurso le quedaba sino pensar diferentemente? La 'diferencia' reside precisamente en que la escritura de Beckett no tiene precedentes y, a su vez, sin sucesores, puesto que ¿qué se podía escribir después de él? Nada. Y es por esta mismísima razón por la cual consideramos a Beckett como un escritor que derriba la Modernidad narrativa. Después de Worstward Ho es el final y no necesariamente, como se ha insistido, que es con El Innombrable.

${ }^{6}$ Lo que es aún más sorprendente es que cuando Uhlmann establece un 'diálogo' entre Beckett y Deleuze jamás discute la rizomaticidad de los textos de Beckett en relación a la elaboración posterior que hace junto a Guattari. 


\section{BECKETT Y LA CRÍTICA}

Nuestro interés en esta sección no es hacer una revisión de la extensísima critica sobre la obra de Beckett, sino considerar algunos artículos y libros que son juzgados como seminales, esto es, estudios que han adquirido un estatuto de primer orden dentro de la crítica sobre la obra del escritor irlandés. No es mi interés tampoco entrar en un debate, puesto que cada investigador tiene derecho a su punto de vista y es claro que no hay un acercamiento a Beckett, sino múltiples. Más bien mi interés reside in situar estas posiciones críticas para demarcarlas de mi propia posición.

Uno de los estudios que encuentro más estimulantes es el de Richard Begam quien sostiene lo siguiente sobre la crítica hacia Beckett:

[...] however, identify two approaches that were specifically influential during the 1950s, 1960s, and 1970s. The first approach, which treats Beckett as a mimetic nihilist, argues that his literature mirrors the fragmentation and alienation of modern life by giving us works that are paradoxical, confusing, absurd. The second approach, which views him as an existential humanist, maintains that he acknowledges the «nothingness» of human existence bur celebrates man's freedom to choose himself as an être-pour-soi. (1996: 7-8)

Con respecto a los dos primeros acercamientos, sin duda existe una voluminosa crítica, pero, muy similar a lo que ocurrió con la crítica sobre Borges alrededor de esos mismos años, esa crítica no podía capturar a Beckett simplemente por que el Post-Estructuralismo sólo comenzó a emerger a mediados de los años 1960, y tomará hasta bien entrados en los años 1980 antes que aquél fuera considerado como una nueva forma de acercarse a la literatura y la cultura. ${ }^{7}$

Uno de los problemas fundamentales con la crítica sobre la obra de Samuel Beckett ha sido la apropiación indiscriminada de sus textos imponiéndole una lectura externa, esto es, una lectura que no surge del texto sino de la posición teórica del crítico, como es el caso ejemplar de Anthony Uhlmann. Así, la obra de Beckett es como el significante flotante de Derrida: queda abierta a cualquiera interpretación. Esto quedó claro en nuestra exposición sobre Beckett y la Modernidad, donde unos lo consideran moderno, o moderno en el límite y otros post-moderno. Lo que todo esto revela es la extrañeza y confusión que plantean los textos de Beckett y la escritura contenida en ellos. Pascale Casanova tiene absoluta razón cuando sostiene que Beckett «figurait à lui seul une sorte d'au-delà poétique, Beckett n'a jamais été lu que comme le messager ou l'oracle de la vérité de 1 " être" »(1997: 7). Es esta fabricación de Beckett la que ha constituido el obstáculo fundamental con respecto a la comprensión de su proyecto.

A parte de las descripciones propuestas por la crítica, citadas más arriba, sobre los diversos acercamientos a la obra de Beckett, Jean Valenti, en un artículo (2006) que consideramos seminal sobre El Innombrable, señala:

\footnotetext{
${ }^{7}$ Es importante tener en cuenta que en el momento mismo que surge el Post-Estructuralismo, la semiótica estructural (Greimas et al) dominaban todo el espació crítico, teórico y cultural, y esto duró hasta fines de los años 1970.
} 
Une vaste gamme de regards sur l'œuvre de l'auteur irlando-français en découlent, si bien que la critique nous propose, comme ne manquent pas de le signaler Lance Butler et Robin Davis, plus d'un «Beckett»: «Beckett as quintessential nouveau romancier, Beckett the Cartesian, Beckett the Existentialist, these have rubbed shoulders with Beckett the Nehilist, Beckett the Mystic and, of course, Beckett the dramatist of the Absurd and Beckett the Explorer of the liminations of language». Énumération fort incomplète au demeurant, car on pourrait aussi y ajouter Beckett le moderniste, voir le postmoderniste. (2006: 199)

Aquí me interesa subrayar el comentario de Lance Butler y Robin Davis citado por Valenti. Si bien es cierto que la crítica sobre Beckett se ha referido a todos estos temas, es, sin embargo, incorrecto considerar a Beckett como un escritor del Nouveau roman, un tipo de novela que se concentra en los objetos, proporcionando una versión personal de los objetos (Moles y Boudon, 1971) y subordinado la trama y los personajes a los objetos que constituyen el mundo, como ha señalado Alain Robbe-Grillet en Pour en nouveau roman: ${ }^{8}$ «Que ce soit d'abord par leur présence que les objets et les gestes s'imposent [...]» y que «Dans les constructions romanesques futures, gestes et objets serons là avant d'être quelque chose [...] (1963 : 23). En cambio en Beckett es precisamente la anulación del 'objeto', puesto que la voz narrativa no describe nada, sólo enuncia un enunciado completamente fracturado, auto-reflexivo, que no apunta sino a sí mismo. Además, lo que postula Robbe-Grillet es que cada escritor crea una nueva novela en cada acto de escritura: «Chaque romancier, chaque roman, doit inventer sa propre forme» (1963: 12), y esto no es para nada el caso en Beckett que, a mi ver, escribe una sola obra. Toda su escritura es un ir hacia Worstward Ho (1996 [1983]), ${ }^{9}$ donde llega al total y completo revestimiento del sentido del lenguaje, sobrepasando en esto a El Innombrable.

Jean Valenti subraya la complejidad de las interpretaciones sobre la obra de Beckett afirmando que

Le conflit des interprétations accentue ici deux pôles diamétralement opposées : interprétations symboli-ques (prolongement de la tradition humaniste) vs inscription de l'œuvre beckettienne dans la déconstruc-tion du sens, du logocentrisme et des grandes mythes territoriaux (le sujet, la conscience, la pensés). (2006: 200)

Habiendo subrayado algunas características centrales sobre la crítica de Samuel Beckett y algunos de los acercamientos y temas centrales con respecto a su producción narrativa, en lo que sigue propongo una mirada diferente, que en términos generales, se aparta de la crítica que ha sido producida hasta ahora. Mi contribución radica no en lo que tengo en común con los estudios brillantes citados, sino en la mirada que intento producir que es otra mirada que no ha estado presente, hasta ahora, en los estudios sobre Samuel Beckett. Por lo tanto sumo mi mirada a todas las otras que a su vez han informado mi mirada. En esto sigo a Roland Barthes, que en «La muerte del autor» (1984) sostiene que el lector es un espacio donde todas las citas se encuentran:

\footnotetext{
${ }^{8}$ Véase también, Jean Ricardou, Problèmes du nouveau roman (1967: 91-121).

${ }^{9}$ Worstward Ho es la penúltima obra de Beckett, publicada en 1983 y re-publicada en 1989 junto a Company y Ill Seen Ill Said en un volumen titulado No how On.
} 
Ainsi se dévoile l'être totale de l'écriture: un texte est fait d'écritures multiples, issue de plusieurs cultures et qui entrent les unes avec les autres en dialogue, en parodie, en contestation; mais il y a un lieu où cette multiplicité se ressemble, et ce lieu, ce n'est, comme l'a dit jusqu'à présent, c'est le lecteur: le lecteur c'est l'espace même où s'inscrivent, sans qu'aucune ne se perde, toutes les citations dont est faite une écriture. (1984: 69)

Se trata, pues, de un lector colectivo donde cada uno aporta algo distinto a los textos de Beckett, dejando siempre abierto el juego de la significación, el cual es infinito como el deslizamiento del sentido de toda su obra; in alcanzable, indecidible, pero el intento de leerlo es inevitable.

\section{EL INNOMBRABLE}

Nuestro interés es leer El Innombrable, como señalamos más arriba, desde otro lugar: desde la deconstrucción que realiza Beckett de la narrativa Moderna y mostrar cómo la lleva a su fin de una forma tan remecedora como cuando muere la arquitectura Moderna en 1979 (Jencks, 1989: 16). Para ello nos centraremos en tres aspectos que consideramos fundamentales desde nuestra perspectiva deconstructivista: ${ }^{10}$ a) la estructura rizomática; b) el fin de la representación; c) la cancelación del sentido y d) el lenguaje y el Sujeto.

\section{BECKETT Y LA ESCRITURA RIZOMÁTICA: EL FIN DE LA ESTRUCTURA NARRATIVA Y DEL RELATO}

Comienzo con una pregunta ineludible: ¿cómo leer a Beckett? Mi reflexión sobre Beckett, y esto es todo lo que podría decir sobre mi posición ante sus textos, parte de la gran extrañeza del proceso de lectura, una lectura que impone un cambio radical en nuestro horizonte de expectativa (Erwartungshorizont, Jauss, 1977) vis-à-vis el texto: un flujo de palabras sin origen, sin comienzo ni fin, un texto dotado de una estructura rizomática, en el sentido de Deleuze y Guattari, siempre en movimiento y con un sentido virtual siempre diferido. Leer a Beckett es re-aprender a leer; esto es inevitable, puesto que de otra forma nos quedamos fuera del texto. Derrida sostuvo al respecto que «Parce que nous commençons à écrire, à écrire autrement, nous devons relire autrement» (De la grammatologie, 1967: 130), y es precisamente en este «autrement» donde se encuentran las condiciones de posibilidad de una lectura diferente.

Pero ¿que significa re-aprender a leer? ¿Y cuál es la lectura diferente? Pues no intentar buscar/encontrar, en la lectura, un relato, un narrador identificable, un sentido oculto, unos personajes reconocibles, una materialización del espacio-tiempo, sino identificar que estamos ante una actividad escriptural sin precedentes y por ello no existe tampoco un precedente de lectura que pueda guiar nuestra lectura o un precedente analítico que puede guiar nuestro análisis. Pero entonces ¿cómo leer? ¿Por dónde comenzar?

\footnotetext{
${ }^{10}$ Deconstructivista en el sentido que Beckett se instala dentro de las estructuras y procedimientos de la novela moderna y los lleva a sus límites, produciendo así su completa invalidación.
} 
Pienso que una de las forma de leer los textos de Beckett es a partir de la noción de estructura rizomática tal cual ha sido establecida por Gilles Deleuze y Félix Guattari en Rihzome (1980). Esta forma de lectura está determinada por los textos beckettianos que consideramos rizomáticos en su conjunto. Para explicar esta forma de lectura es necesario precisar la noción de estructura rizomática, particularmente con respecto a cuatro principios fundadores: conexión, multiplicidad, heterogeneidad, y a-significación. Estos cuatro principios, son, de hecho, tautológicos en la medida que cado uno refiere a los otros. Todo rizoma se caracteriza por conexiones heterogéneas múltiples, donde la alteración de un segmento de la estructura no afecta a la estructura en su conjunto, por lo tanto una ruptura o línea de fuga al no ser significativa, esto es, a-significante: el rizoma es nomádico y está siempre en movimiento desterritorializándose, reterritorializándose para formar un nuevo territorio. Este es el moviendo del rizoma y por ello de la lectura y del análisis, y es lo que define la estructura rizomática del texto beckettiano. Así, el rizoma es infinito, no tiene ni principio ni fin ni origen. Deleuze y Guattari señalan al respecto que el rizoma es como un mapa:

La carte est ouvert, elle connectable Dans toutes ses démentions, démontable, renversable, susceptible de recevoir constamment des modifications. Elle peut être déchirée, renversée, s'adapter à des montagnes de toute nature, être mise en chantier par le individu, un groupe, une formation sociale. (1980: 20)

Junto con esta descripción de Deleuze y Gauttari, podríamos ejemplificar el rizoma de una forma visual:

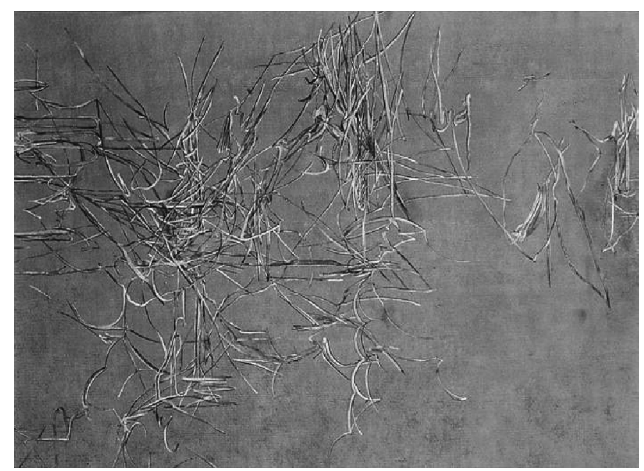

La nomadicidad/rizomaticidad textual puede ser contenida por medio de una lectura isotópica, esto es por multiplicidades que forman territorios marcados por una isotopía también nomádica. Entendemos como isotopía «[...] le concept d'isotopie a désigné d'abord l'itérativité, le long d'un chaîne syntagmatique, de classèmes qui assurent au discours-énoncé son homogénéité (Greimas y Courtés, 1979: 197). Aquí es importante señalar que la isotopía la empleamos como isotopía semántica y no sintáctica, puesto que al nivel sintáctico no es operatoria en Beckett. La isotopía semántica nos proporciona una mínima estabilidad de lectura. 
La estrategia textual de Beckett consiste en desarticular tanto la sintaxis como el sentido textual. Hay aquí dos niveles de análisis, uno sintagmático y otro semántico. Puesto que la estructura textual, esto es el sintagma narrativo es rizomático, no existe un relato, esto es, no se relata nada que pueda ser estructurado fuera del rizoma: la estructura no tiene ni principio ni fin y el texto comienza y termina de una forma circular y puede ser leído y terminado en cualquier punto de la estructura rizomática. La única forma de establecer el movimiento rizomático es por medio de las isotopías semánticas, las cuales no hacen sino revelar la estructura rizomática del texto.

Esta lectura que proponemos no viene dictada del exterior del texto, sino del texto mismo, puesto que el texto, insistimos, es rizomático y su estrategia es tanto la implosión de la estructura, como de la voz narrativa, sin origen ambas, y del sentido (nos ocuparemos de estos dos últimos aspectos más abajo).

Así, Samuel Beckett produce en todos sus textos una estructura rizomática, esto es, una estructura nomádica y aleatoria donde toda posible diegésis es implotada fragmentándose en astillas. El texto, a través de la voz narrativa que lo constituye, insistimos, no tiene ni comienzo ni fin, no tiene origen en un punto de partida diegético y la voz narrativa se despliega en la planicie topográfica donde se inscribe: termina como comienza:

The fact would seem to be, if in my situation one may speak of facts, not only that I shall have to speak of things of which I cannot speak, but also, which is even more interesting, but also that I, which is if possible even more interesting, that I shall have to, I forget, no matter. And at the same time I am obliged to speak. I shall never be silent. Never. (1955: 291)

$[\ldots]$

[...] it will be I, you must go on, I can't go on, you must go on, I'll go on you must say words, as long s there are any, until they find me, until they say me, strange pain, strange sin, you must go on, perhaps they have carried me to the threshold of my story, before the door that opens on my story, that would surprise me, if it opens, it will be I, it will be the silence, where I am, I don't know, I'll never know, in the silence you don't know, you must go on, I can't go on, I'll go on. (1955: 414)

Esta circularidad rizomática viene determinada por la estructura interna misma del rizoma, es decir, el texto se despliega a partir de la constitución de territorios (Deleuze y Guattari, 1980), que son desarticulados por líneas de fuga que los desterritorializan para crear una reterritorialización (1980: 15-16, 19. Así, el rizoma se desarrolla siempre en una expansión nomádica que no permite trazar una estructura definible. Este es el movimiento permanente del texto, que repite incesantemente el movimiento tripartito por medio de las líneas de fuga.

La pregunta que surge en el curso de la lectura, es ¿cómo capturar algún sentido en un texto que bloquea toda posibilidad expresión significativa del lenguaje puesto que no hay nada que descodificar? La única posibilidad es de comprender la estrategia del texto, esto es, qué permite el texto leer en esa estrategia. La estructura rizomática produce isotopías, esto es, momentos de estabilidad de sentido donde la voz narrativa se centra en un 'tema', creando rupturas por medio de líneas de fuga que se organizan de la siguiente manera; a modo de ejemplo: 
1. Aporía: pp. 291-292

2. Personajes: Malone, Molloy, Murphy: pp. 292-295

3. Silencio: pp. 295-296

4. Choque con el tiempo: 296-300

5. No poder ver, hablar: $300-303$

6. Voy a hablar: 303304

7. La disolución del cuerpo: 304-306

8. Detener las preguntas: 306-308, etc.

Estos breves ejemplos isotópicos revelan la implosión textual pero a su vez señalan la existencia de sub-isotopías, esto es, micro-isotopías dentro de una macro-isotopía. Esta realidad sub-isotópica astilla el texto de tal manera que hace completamente imposible una lectura que busque un sentido. Por ejemplo, algunas isotopías centrales son: el silencio, el hablar, Worm, Manhood, constantemente recomenzar, etc.

La implosión de la estructura por medio de la rizomaticidad es una de las formas en que Beckett lleva a su fin la Modernidad narrativa. No solamente oblitera toda noción de estructura narrativa, sino que a su vez hace imposible cualquier posibilidad de acercamiento estructuralista. Menciono esto puesto que una década después de la publicación de El Innombrable (1955), surgirá el estructuralismo como la forma de acercarse a la literatura, antropología, cine, etc. Por ello no es sorprendente que el estructuralismo jamás se ocupara o prestara atención alguna a la obra de Beckett puesto que venia a insertarse directamente en la forma de encarar el lenguaje, la estructura, el Sujeto, etc., del Post-Estructuralismo, adelantándose así a las problemáticas propias del Post-Estructuralismo. ${ }^{11}$

\section{BECKETT Y EL FIN DE LA REPRESENTACIÓN}

La representación ha sido algo central en toda la literatura y las artes de Occidente desde los griegos en adelante. Aristóteles define y especifica la noción de $\mu$ junбıৎ imitatio, en la Poética, de la siguiente manera:

Éstas son, por consiguiente, las tres diferencias posibles en la imitación, como dijimos al principio; los medios, los objetos y el modo de imitarlos. (García Yebra, 1974: 1448a11-26; 3: 133)

$[\ldots]$

Y también resulta claro por lo expuesto que no corresponde al poeta decir lo que ha sucedido, sino lo que podría suceder, esto es, lo posible según la verosimilitud o la necesidad. En efecto, el historiador y el poeta no se diferencian por decir las cosas en verso o en prosa [...]; la diferencia está en que uno dice lo que ha sucedido, y el otro, lo que podría suceder. (1974: 1451b 1-21, 9: 158)

Cuando Aristóteles define la imitación de esta forma, abre la puerta para dos cosas: primero que la imitación se centra en 'objetos', esto es, en algo concreto que representar (concreto en el sentido amplio, que puede indicar ideas, pensamientos, sentimientos,

${ }^{11}$ Sin embargo, debemos recordar que a pesar de que muchas de las obras seminales del Post-Estructuralismo fueron escritas en los años 1960, el impacto de esta producción no se sentirá sino hasta fines de los años 1970 y particularmente en los años 1980. 
etc.,). Así, lo exterior pude ser representado por diversas maneras, tales como por el lenguaje o el dibujo. De este modo, la imitación representa siempre algo que tiene, de algún modo, un referente; segundo, separa la creación literaria y artística de la Historia. Esto es, a partir de Aristóteles el creador queda libre para ficcionalizar puesto que no está sujeto a representar lo que sucedió sino lo podría haber sucedido. Estas dos características de la representación permanecerán casi sin alteración hasta bien entrado el siglo XX, comprendiendo, en esto, la literaturas y las artes modernas. Por más abstracta que pueda presentarse la pintura o la literatura de la Modernidad (Picasso y Joyce) esta definición queda allí, intacta: alterada, deformada, pero la huella del imitatio no es obliterada.

El cuestionamiento de la capacidad del lenguaje para representar y expresar es sin duda lo que Beckett oblitera: en El Innombrable desaparece todo lo que podría asemejarse a la representación y el texto se astilla in infinitas inscripciones del lenguaje. ¿Qué es lo que oblitera Beckett? Pues el lenguaje y el relato como lo habíamos conocido desde los griegos hasta la Modernidad. En El Innombrable no hay narrador, sino una voz sin origen que no narrada nada, sólo enuncia un enunciado incomprensible: el narrador se disuelve en una voz, en un sonido de palabras inarticuladas y carentes, como la estructura rizomática del texto que la voz inscribe, de toda dirección; implota el relato puesto que no hay ni un vestigio de historia a contar: se trata del deambular nomádico de una voz que busca constituirse en Sujeto de la enunciación sin lograrlo; no hay nada que pueda constituirse como ficción, ya que no se ficcionaliza ningún 'objeto': no hay objetos en los cuales se centre la voz que escuchamos; la voz no se dirige a ningún lector, sino que es reflexiva: se refiere a sí misma. Es por estas razones que es imposible, a mi ver, no solamente considerar a Beckett como un escritor de la Modernidad, sino también porque su escritura no tiene nada que ver con la novela en el sentido que Luckács la ha definido (1971): se trata solamente de un texto, de una masiva heteroglosia y de un dialogismo interno de la voz narrativa.

Así, Beckett lleva a su fin la noción misma de estructura narrativa reemplazándola por una estructura rizomática que es inasible y por lo tanto imposible de sistematizar. Junto a esto, liquida toda noción de representación, al menos como ésta se ha entendido desde Aristóteles hasta el fin de la Modernidad que Beckett, como Cage en música o Pollock en pintura, se encarga de obliterar. Pero esto no es todo: Beckett construye un lenguaje del silencio, donde las palabras disuelven el sentido dejando la pura sonoridad del lenguaje. Silencio en cuanto el lenguaje no dice nada develando la pura materialidad del significante desinvertido del significado.

\section{BECKETT Y LA PROBLEMÁTICA DEL SUJETO}

Más allá de cualquiera consideración de orden puramente filosófico con respecto al Sujeto, soy de la opinión que la problemática que trata Beckett en su obra literaria tiene que hacer con una condición aporística del Sujeto en su intento de lograr alguna forma de identidad que esté más allá del lenguaje. La problemática del Sujeto en Beckett está íntimamente vinculada a la lengua.

La problemática entre el Sujeto y el lenguaje se articula en un sólo tema central: la no pertenencia del lenguaje: quien habla es el Sujeto de la lengua y no del Sujeto que habla quien se vale de una lengua que no le pertenece. Este tema central, que constituye la problemática de la escritura beckettiana, se materializa y se constituye, 
a su vez, en dos temas fundamentales que atraviesan todo el texto de El Innombrable y, de hecho, toda la obra de Beckett: 1) la expresión aporística del Innombrable que oscila entre el silencio y la necesidad de hablar y 2) la anulación del sentido por medio del vaciamiento semántico y la autoanulación de toda afirmación. Jean Valenti sostiene sobre esta problemática, lo siguiente:

L'Innomable se présente comme la mise en scène d'un moi à la recherche d'une révélation identitaire, mais aux prises avec des voix mentales impossible à escamoter. (2006: 204)

Estos dos temas son distintas formas de referirse al mismo problema: la imposibilidad de expresar nuestra subjetividad por medio del lenguaje.

Antes de centrarnos en estos dos temas, es preciso, sin embargo, referirnos a la problemática del Sujeto en cuanto es el intento del Sujeto en constituirse como tal, lo que da pié al movimiento aporístico de la voz que escuchamos, a la naturaleza del silencio y a su necesidad de hablar, y a la anulación del sentido.

Una forma de encarar esta problemática, en términos generales, es pensar con Lacan, el Sujeto en Beckett, particularmente en El innombrable. Lacan sostiene en Los cuatro conceptos fundamentales del psicoanálisis, que «L'inconscient est la somme des effets de la parole sur un sujet, à ce niveau où le sujet se constitue des effets du signifiant» (1973 : 116). Lo que Lacan sostiene aquí es que el Sujeto se constituye por el lenguaje (el significante) y esto implica que el Sujeto es un efecto del lenguaje y por lo tanto es constituido por el lenguaje: ${ }^{12}$

Si le sujet est ce que je vous enseigne, à savoir le sujet déterminé par le langage et la parole, cela veut dire que le sujet, in initio, commence au lieu de l'Autre, en tant que là sur surgit le premier signifiant. (1973: 180).

Y el Sujeto es simbolizado por una S con una barra oblicua sobre él [S], esto es, un Sujeto que se constituye en el Otro, el Sujeto como carencia: «[...] Dans notre vocabulaire à nous, nous symbolisons par $\mathrm{S}$ barré $[\mathrm{S}]$ le sujet, en tant que constitué comme second par rapport au signifiant. (1973: 129). Esta relación del Sujeto inscrita en el Significante, esto es en el Otro, es lo que determina el lenguaje de la voz del Innombrable. La problemática fundamental, esto es, la situación aporística del Sujeto, reside en esto: si, como afirma Lacan, el Sujeto nace en la lengua y es constituido por el lenguaje y su conciencia de sí sólo emerge del y por el lenguaje, entonces ¿quién habla, el Sujeto o el Sujeto de la lengua? Siguiendo a Lacan y a Barthes podemos decir con certeza que es el Sujeto de la lengua quien habla y el Sujeto empírico desaparece detrás del Sujeto de la lengua. La aporía se instala cuando el Sujeto debe hablar para tener conciencia de sí, por que de otra forma no existe, pero este hablar le anula su propia subjetividad la cual se desliza detrás del Sujeto de la lengua.

\footnotetext{
${ }^{12}$ Keith C. Pheby señala al respecto: «Subjects don't use language(s) as if they were outside of languages because, as centers of consciousness, subjects are always already constituted linguistically» (1988: 54).
} 
Estas reflexiones que acabamos de proponer están determinadas, en el caso de El Innombrable, por las palabras mismas del Sujeto, la voz sin origen que nos habla:

I seem to speak, it is not I, about me, it is not about me. These few general remarks to begin with. What am I to do, what shall I do, what should I do, in my situation, how to proceed? By aporia pure and simple? Or by affirmations and negations invalidated as uttered, or sooner or later? (1955: 291)

Lo que se establece desde el comienzo es la necesidad ineludible de hablar, y el reconocimiento de que este hablar no es su expresión sino la del lenguaje. Así, la situación aporística se instala desde el inicio mismo del texto, e incluso la voz se refiere a la aporía. Así, en la primera página se establece toda la estrategia textual, esto es, la voz aporística (veremos esto en más detalle en la sección b) y su forma de proceder y, a la vez, la cancelación permanente y recíproca de los enunciados ante la incapacidad del lenguaje de decir nada y la introducción de los dos temas fundamentales: hablar/silencio inscritos en la aporía.

El Innombrable es completamente conciente de que quien habla no es él (I) pero que debe hablar para tener conciencia de sí, y es conciente de que las palabras que emite no le pertenecen ni lo expresan: «I who am here, who cannot speak, cannot think, and who must speak [...]» (1955: 301). El texto manifiesta constantemente la imposibilidad de que el Sujeto encuentre su propia voz:

And perhaps now again I shall do no more than seek my lesson, to the self-accompaniment of a tongue that is not mine. (1955: 301)

El lenguaje se presenta como algo exterior, algo que acompaña al Sujeto, pero que ese lenguaje no le pertenece. Es esta realidad a la cual alude Rolan Barthes cuando sostiene que: «Qui parle ainsi? [...]. Il sera à jamais possible de le savoir pour la bonne raison que l'écriture est la destruction de toute voix, de toute origine» (1984: 63). Si la escritura «es la destrucción de toda voz», entonces podemos afirmar que el asumir el lenguaje también constituye la cancelación de toda voz (subjetividad). La cancelación de la diferencia entre escritura y acto verbal ha sido clara y definitivamente establecida por Jacques Derrida cuando señala que:

Il faut maintenant penser que l'écriture est à la fois plus extérieur à la parole, n'étant pas son «image» ou son «symbole», et plus intérieur á la parole qui est déjà en elle-même une écriture. (1967: 68)

[...]

La parole puise donc à ce fond d'écriture, note ou non, qu'est la langue, et c'est ici qu'on doit méditer la connivence entre les deuz «fixités». (1973: 78)

Es esta posición derridiana la que nos lleva a conectar la voz del Innombrable con la posición barthesiana con respecto a la escritura. El Sujeto, pues, desaparece tanto en el acto de escritura como en el acto de palabra.

En El Innombrable recurrentemente nos tropezamos con un 'They' (ellos), que parecería ser abstracto, pero no lo es, por el contrario, creo el 'Ellos' es el 'Otro' desde donde el Innombrable obtiene su subjetividad refractada: 
[...] They say they, speaking of them, to make me think it is I who am speaking. Or I say they, speaking of God knows what, to make me think it is not I who am speaking. (1955: 370)

El Innombrable se inscribe en un gesto contradictorio de autoanulación: por una parte, 'Ellos' le dicen que es Él quien habla, haciéndole creer que Él es el Sujeto que habla y no la lengua, por otra parte, le señalan que Él es un efecto de discurso, puro lenguaje. Esto es precisamente lo que sostiene Lacan cuando afirma que,

Vous aurez à y voir que c'est dans l'Autre que le sujet se constitue comme idéal, qu'il a à régler la mise au point de ce qui vient comme moi, ou moi idéal - qui n'est pas l'idéal du moi - c'est-à-dire, à se constituer dans sa réalité imaginaire. (1973: 132).

La conciencia del Innombrable de que el lenguaje no le pertenece es recurrente en el texto y se establece desde el inicio mismo; pero además, subraya el hecho de que las palabras no tienen sentido alguno. Así dice:

[...] Where do these words come from that pour out of my mouth, and what do they mean, no, saying nothing, for the words don't carry any more, if one can call that waiting [...]. (1955: 370)

$[\ldots]$

[...] I'am in words, made of words, other's words, what others, the place too, the air [...] I'am all these words, all these strangers, this dust of words, with no ground for their settling, no sky for their dispersing [...]. (1955: 386)

Y, a su vez, se reconoce como constituido por las palabras, como un efecto de lenguaje y por ello no existe ninguna posibilidad de establecer cualquier tipo de identidad, subjetividad o conciencia de sí mismo, como lo de muestran los pasajes siguientes:

[...] with regard to me, that it has not yet been our good fortune to establish with any degree of accuracy what I am, where I am, whether I am words among words, or silence in the midst of silence [...]. (1955: 388)

[...] I have no faith in it, none, so that I have to say, when I speak, Who speaks, and seek, and so on and similarly for all the other things, for things that happen [...]. (1955: 391)

Estos pasajes revelan insistentemente la imposibilidad de expresarse, la conciencia de que las palabras que enuncia no le pertenecen, es solamente la lengua que habla. Los pasajes dejan en claro la situación aporística del Innombrable: el Sujeto cartesiano se constituye por el Cogito ergo sum, es el pensar lo que constituye al Sujeto, pero en Beckett como en Lacan es: yo hablo por eso soy. La aporía surge de esta contradicción insuperable: si no hablo no soy, ya que sólo puedo constituirme en el lenguaje, pero al hablar el sujeto de la lengua me desplaza y desaparezco detrás del significante (el lenguaje). Es el inconciente del Innombrable que busca establecerse como Sujeto, pero no puede. Lacan sostiene al respecto que:

Mais, certes, c'est dans l'espace de l'Autre qu'il se voit, et le point d'où il se regarde est lui aussi dans cet espace. Or, c'est bien ici aussi le point d'où il parle, puisqu'en tant qu'il parle, c'est au lieu de l'Autre qu'il commence à constituer ce mensonge véridique par où s'amorce ce qui participe du désir au niveau de l'inconscient. (1973: 132)

Desde el punto de vista de la escritura beckettiana, el desdoblamiento del Sujeto en Yo/Ellos/El presenta perfectamente la proyección del Yo al Otro, y en esto estriba 
también el relato: el inconciente es el lugar del Otro, y como Lacan afirma, «[...] l'inconscient c'est le discours de l'Autre (1973: 119). Lo que motiva el movimiento rizomático de la voz narrativa beckettiana es una carencia de base (- $\varnothing)$ que se manifiesta en una fantasía: encontrar la voz escondida detrás del Sujeto de la lengua: S a $\left[\begin{array}{ll}S & \mathrm{D}\end{array}\right]$.

La problemática del Sujeto tiene que hacer también, en Beckett, con la desaparición del Sujeto o el desplazamiento del Sujeto metafísico, y yo añadiría, la fragmentación del Sujeto. Lo que se desplaza es el Sujeto cartesiano como señala Keith C. Pheby: «[...] the philosophical subject, particularly since the hegemony of the Cartesian cogito, is conceived as the self-identical center of certainty, the locus of truth» (1988: 6). El Sujeto metafísico cartesiano es constituido ahora por el lenguaje, y no lo será solamente el del psicoanálisis, sino también el de la filosofía. Martin Heidegger en Unterwegs zur Sprache señala que

[...] Sie spricht einzig und eisam mit sich selber. Ein Satz des Textes lautet: «Gerade das Eigentümliche der Spachem daß sisich bloß um sich selbst bekümmert weisß keiner« (1959: 241)

$[\ldots]$

Und sie spricht aunsam. (1959: 254) $)^{13}$

Estas afirmaciones de Heidegger demuestran que el Sujeto tiene poco o nada que hacer con el sentido previo de la lengua: nacimos a la, en la y por lengua y la trace, esto es la huella del sentido se nos escapa. La lengua, como señala Pheby es «[...] the site for the «self-emerging and self-unfolding power of life and at the same time the excluded supplement of Greek «einai» comes to presence» (1988: 15). Es de esto de lo cual nos habla Heidegger al referirse a Sein como el sentido llegando a la presencia y al thia, lo que se revela. La voz del Innombrable fluctúa precisamente en el intento de llegar a ser y de emerger con su propia voz, lo cual viene a confirmar la aporía a la cual se enfrenta. La aporía emerge puesto que «[...] language is the field of our experience and discourse, the medium through which the world becomes articulated, it is at one and the same time the limit of experience» (188: 43).

La sola posibilidad de derrotar al lenguaje, es vaciarlo de todo sentido (como veremos en la sección (c) más abajo), ya que intentar no hablar es imposible, pero hablar también significa auto-anularse.

[...] I'll speak of me when I speak no more. In any case it's not the question of speaking of me, but of speaking, of speaking no more [...]. (1955: 392)

El 'Ellos', a mi ver, constituye diversas versiones del Innombrable presentes en textos anteriores a El Innombrable: 'Ellos' y a las variaciones/versiones de 'Ellos' son

\footnotetext{
${ }^{13}[\ldots]$ la lengua habla con ella mi9sma sola y solitariamente. Una frase en el texto dice asçi:»-lo que precisamente es peculiar de la lengua.que se centra solamente conella misma - nadie sabe».

$[\ldots]$

[...] es solamente la lengua la que propiamente habla en soledad. (La traducción es nuestra).
} 
el Otro desde donde habla el Innombrable. Sin duda, hasta este texto, todos los anteriores parecerían ser un viaje a éste, con la prolongación a Worstward Ho, y esto se establece en el texto de una forma periódica:

It is I invented him, him and so many others, and the places where they passed, the places where they stayed, in order to speak, since I had to speak, without speaking of me, I couldn't speak of me, I was never told I had to speak of me, I invented my memories, not knowing what I was doing, not one is of me, it is they asked me to speak of them, they wanted to know what they were, how they lived, that suited me, I though that would suit me, since I had nothing to say and had to say something, I though I was free to say any old thing, so long as I didn't go silent. Then I said to myself that after all perhaps it wasn't any old thing I was saying, that is might well be the thing I was saying, that it might well be the thing demanded of me, assuming something was being demanded of me. (1955: 396)

Estos textos revelan con una extrema claridad la constitución del Sujeto en el Otro, la cual se va a materializar en una serie de nombres pertenecientes a textos anteriores a El Innombrable:

I naturally thought of the pseudocouple Mercier-Carmier. (1955: 297)

$[\ldots]$

Wrong, I continue to see Malone as darkly as the visibility permits [...]. (1955: 297)

$[\ldots]$

One in particular, Basil I think he was called, filled me with hatred. (1955: 298)

$[\ldots]$

All these Murphys, Molloys and Malones do not fool me. They have made me waste my time, suffer for nothing, speak of them when, in order to stop speaking, I should have spoken of me and me alone. (1955: 303)

$[\ldots]$

For if I am Manhood, I am Worm too. Or if I am not yet Worm, I shall be when I cease to be Manhood. (1955: 338)

Estas citas claramente subrayan lo que venimos afirmando: el Innombrable se constituye en el Otro (Murphy, Manhood, Molloy, Worm, etc.) y es através de ellos que asume el lenguaje; pero sabe, a la vez, que este acto de lenguaje es un acto fallido, ya que oculta su propia voz, como claramente lo establecen las citas 4 y 7 .

Resumiendo: la razón por la cual el Sujeto beckettiano se sitúa en una posición aporística es debido que la lengua no puede expresar su Ser: la lengua desplaza al verdadero Sujeto y lo oculta en el Sujeto de la lengua. El Sujeto beckettiano lucha por emerger (al thia) para constituirse en Sein. Así, queda atrapado en a una cadena sisifiana de palabras que no significan nada, excepto su intento de expresar, donde un enunciado cancela el anterior en un movimiento perpetuo. Su única realidad es asumir una posición scópica.

\section{LA EXPRESIÓN APORÍSTICA DEL INNOMBRABLE: SILENCIO Y LA NECESIDAD DE HABLAR}

Uno de los rasgos salientes del movimiento aporístico es la voz que oscila entre el silencio y la necesidad de hablar. La necesidad de hablar viene determinada del deseo del 
Innombrable de ser Sujeto de la enunciación y del enunciado, es decir, del intento aporístico de eliminar la lengua como Sujeto donde el Sujeto narrativo pueda llegar a expresarse:

When all goes silent, and comes to an end, it will be because the words have been said, those it beloved to say, no need to know which, no means of knowing which, they'll be there somewhere, in the heap, in the torrent, not necessarily the last, they have to be ratified by the proper authority, that takes time, he's far from here, they bring him the verbatim report of the proceedings [...] (1955: 369)

$[\ldots]$

This silence they are always talking about, from which supposedly he came, to which he will return when this act is over, he doesn't know what it is, nor what is meant to do, in order to deserve it. (1955: 376)

$[\ldots]$

[...] that it has not yet been our good fortune to establish with any degree of accuracy what I am, where I am, whether I am words among words, or silence in the midst of silence [...]. (1955: 388)

$[\ldots]$

The silence, a word on the silence, in the silence, that's the worst, to speak of silence, then lock me up, lock someone up, that is to say, what is that [...]. (1955: 405)

Hemos seleccionado estos ejemplos de la aporía hablar/silencio simplemente para demostrar que este es un tema fundamental en el texto. El silencio no es a lo que la voz desea llegar, sino el silencio es escuchar una/su voz que no reconoce, el silencio de su voz y de aquí la ineludible necesidad de continuar hablando para intentar llegar a su voz que finalmente cancelaría el silencio. Sin embargo, este intento es un puro deseo fallido, y de aquí emerge la dimensión aporística del movimiento textual y su rizomaticidad. El lenguaje del innombrable es el silencio mismo: el estar siempre recomenzando su intento de voz constituye el silencio del cual habla.

A su vez la voz es conciente de que cuando habla no es ella la que habla, es decir, el Sujeto está conciente de que es solamente un vehiculo, su voz, para que hable el lenguaje sobre el cual no tiene ningún control:

But this voice continued to testify for me, as though woven into mine, preventing me from saying who I am, what I was, so as to have done with saying, done with listening. (1955: 309)

Precisamente, la voz que se entre mezcla con la suya, es la voz del Otro (el Significante/el Lenguaje), no solamente se mezcla, sino que la/lo anula: es algo inescapable. Es este Otro que le impide saber quien es: la única forma de ser es constituirse en/por el Otro, pero esto significa la anulación de su propia subjetividad. Lacan señala al respecto que «[...] naître avec le signifiant, le sujet naît divisé. Le sujet, c'est ce surgissement qui, juste avant, comme sujet, n'était rien, mais qui, à peine apparu, se fige en signifiant» (1973: 181). El Innombrable es consumido por la tragedia del lenguaje que mata al Sujeto:

Where do these words come from that pour out of my mouth, and what do they mean, no, saying nothing, for the words don't carry any more [...]. (1955: 372) 
Este pasaje es uno de los más revelantes de todo el texto por dos razones: primero, de una forma explícita, subraya el hecho de que las palabras no le pertenecen, lo cual reconfirma lo que hemos venido diciendo a lo largo de este estudio. Esta afirmación del Innombrable se inserta directamente dentro de la teoría post-estructuralista con respecto al lenguaje y al autor; segundo, reconoce que las palabras no tiene sentido, que es imposible que las palabras puedan llegar a expresar puesto que no contienen ninguna significación capaz de aprehender la expresión. Estas citas demuestran claramente la necesidad de hablar para poder ser, pero al mismo tiempo impiden poder ser porque el Sujeto narrador se desliza debajo del Sujeto del lenguaje.

El silencio, como señalamos más arriba, es el silencio de su voz, pero, a la vez, el no continuar hablando es una forma de anularse a sí mismo ante la aporía, esto es, resolver la aporía anulándose:

So it is I who speak, all alone, since I can't do otherwise. No, I am speechless. Talking of speaking, what if I went silent? (1955: 307)

$[\ldots]$

Silence, yes, but what silence! For it is all very fine to keep silence, but one has also to consider the kind of silence one keeps. (1955: 309)

$[\ldots]$

[...] words falling, you don't know where, you don't know whence, drops of silence through the silence, I don't feel it [...]. (1955: 382)

El Sujeto termina por donde comenzó, esto es, en el permanente movimiento de intentar sobrepasar la aporía. Así, está condenado a desplazarse en el tiempo arrastrando la lengua que lo oculta. Su única posibilidad de no decir la lengua, de impedir totalmente que el Sujeto de la lengua lo consuma, es llevando el lenguaje al sin sentido absoluto:

[...] it will be I, you must go on, I can't go on, you must go on, I'll go on you must say words, as long s there are any, until they find me, until they say me, strange pain, strange sin, you must go on, perhaps they have carried me to the threshold of my story, before the door that opens on my story, that would surprise me, if it opens, it will be I, it will be the silence, where I am, I don't know, I'll never know, in the silence you don't know, you must go on, I can't go on, I'll go on. (1955: 414)

\section{BECKETT Y LA CANCELACIÓN DEL SENTIDO}

Una rasgo fundamental de la obra de Samuel Beckett es el sin sentido de sus obras, sin sentido con respecto a que allí no se relata ninguna historia, no hay nada que se pueda parecer a una voz narrativa que atribuya sentido, ni nada que se asemeje a personajes, sin contar con una vacuidad total de tiempo y espacio narrativo. La postura de Beckett es que el lenguaje simplemente no obedece para nada a la articulación interna del significante y el significa o la articulación externa del signo con el referente. Esto decididamente oblitera cualquiera posibilidad de producción de sentido tal cual se entendió, por ejemplo, hasta el estructuralismo. Lo que hace Beckett es devestir la lengua de toda significación presentándonos a cambio significantes puros, esto es, la lengua como pura materialidad, foné, grafía; un lenguaje sin origen, sin finalidad, tautológico en cuanto sola- 
mente ser refiere a sí mismo, en lo que llamaría un movimiento fractal infinito, reproduciendo lo mismo en lo mismo, que puede ser visualizado de la siguiente forma:

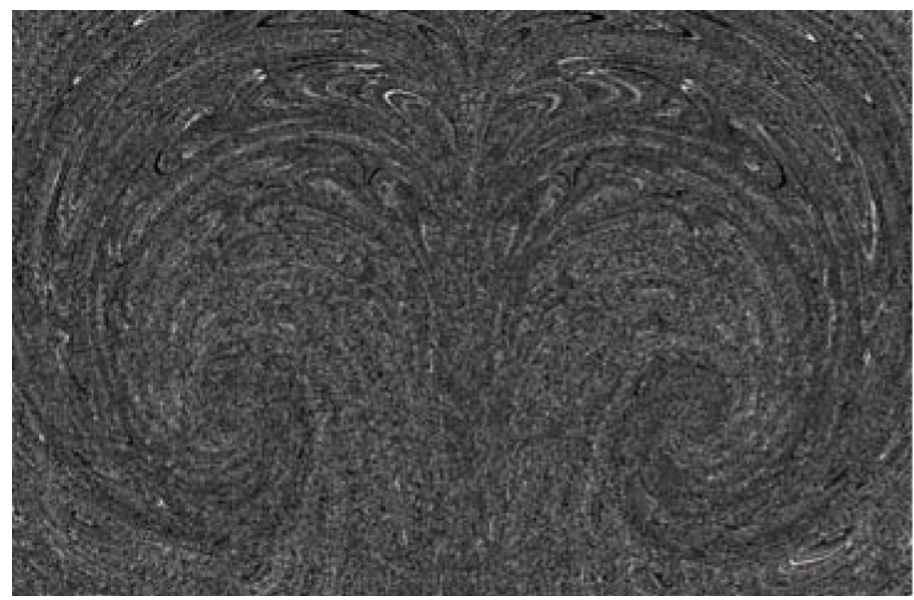

Es por esto que el texto no tiene ni principio ni fin, es como un corte aleatorio (random) transversal en una planicie: hay un antes y un después virtual, pero no contenido en el texto.

Existen al menos dos mecanismos de cancelación del sentido en El Innombrable: 1) la auto cancelación de todo enunciado, y 2) el constante recomenzar a hablar. En lo que sigue nos concentraremos en estros dos aspectos para concluir esta primera aproximación a Beckett.

\section{LA AUTO CANCELACIÓN DE TODO ENUNCIADO}

En el movimiento aporístico y rizomático del texto reproduce la auto cancelación del sentido. Este movimiento y esta cancelación, que forman la rizomaticidad, es constante, y esto revela la capacidad del Innombrable a expresarse y, consecuentemente, conduce inevitablemente a bloquear el sentido. Daremos solamente unos ejemplos puesto que todo el texto funciona de esta forma. El texto comienza con la auto cancelación del sentido y concluye de la misma manera:

The fact would seem to be, if in my situation one may speak of facts, not only that I shall have to speak of things of which I cannot speak, but is if possible even more interesting, that I am obliged to speak, I shall never be silent. Never. (1955: 291)

Aquí hay dos cancelaciones: anuncia que va a hablar de hechos, pero no hay hechos de que hablar y que va hablar de cosas sobre las cuales no puede hablar. Luego, al final leemos:

[...] it will be I, you must go on, I can't go on, you must go on, I'll go on, you must say words, as long as there are any, until they find me, until they say me, strange pain, strange sin, you must go on, perhaps it's done already, perhaps they have said me already, perhaps they have carried me to the threshold of my story [...] $(1955: 414)$ 
El inicio y el final marcan la fracticidad del texto que se repite a sí misma sin detenerse en ningún instante como lo demuestran los siguientes pasajes:

All has proceeded, all this time, in the utmost calm, the most perfect order, apart from one or two manifestations the meaning of which escapes me, No, it not that their meanings escapes me, my own escapes me just as much. (1955: 293-294)

[...]

Ah his blind voice, and these moments of head breath when all listen widely, and the voice that begins to fumble again, without knowing what it's looking for, for what, no one knows, a sign of life perhaps, that must be it a sign of life escaping someone [...]. (1955: 372)

$[\ldots]$

[...] but there it is, fear of sound, fear of sounds, the sounds of beasts, the sounds of men, sounds of daytime and sounds at night, that is enough, fear of sounds, all sounds, more o less, more or less fear, all sounds, there's only one, continuous, day and night, what is it, it's steps coming and going, it's voices speaking for a moment [...]. (1955: 387)

Las características de estos pasajes son: la auto-cancelación de toda afirmación presente en todos los textos citados; el eterno recomenzar a hablar y la circularidad del texto. Así, estos son aspectos centrales de la escritura beckettiana: deslizamiento del sentido, auto-cancelación de enunciados y escritura rizomática. Es esta estrategia de auto-cancelar los enunciados que conduce a la cancelación del sentido, puesto que no hay ninguna posibilidad de derivar de aquéllos alguna forma de significación. Lo que Beckett oblitera es la lógica proporcional (Wittgenstein, 1921: 224), y por ello, conduce al fin del sentido, donde ninguna proposición puede ser determinada como verdadera/falsa. Beckett lleva el lenguaje al 'otro lado del límite' y es por esto que su escritura,/lenguaje no solamente no remite a nada, ni al mundo de los objetos o hechos (Wittgenstein, 1921: 199-200), y de aquí el sin sentido.

\section{EL CONSTANTE RECOMENZAR A HABLAR}

Otra forma de cancelar el sentido en El Innombrable se da a través del recurso de estar constantemente recomenzando el acto de hablar. Este aspecto, como el de la auto-cancelación se despliega a lo largo del texto:

The best would be not to begin. But I have to begin. That is to say I have to go on. (1955: 292)

$[\ldots]$

[...] Enough questions, enough reasoning, I resume, years later, meaning I suppose that I went silent, that I can go silent. (1955: 308)

$[\ldots]$

First I'll say what I'am not, that's how they taught me to proceed, then what I am, it's already under way, I have only to resume at the point I let myself be cowed. (1955: 326)

[...]

So long as one does what one is saying and can't stop to inquire, in tranquility, fortunately, fortunately, one would like to stop, but unconditionally, I resume, so long as, so long as let me see, so long as one, so long as he [...]. (1955: 399) 
He citado todos estos pasajes para ilustrar lo que sostuve al comienzo de esta sección y para subrayar este eterno recomenzar de la voz del Innombrable. Un aspecto saliente es la carencia nemónica de la voz, que habla no sólo sin entender lo que dice, sino que tampoco retiene nada de lo que dice: «[...] if I could remember what I have said I could repeat it, if I could learn something by heart I'd be saved, I have to keep on saying the same thing [...] (395). Así, el acto de lenguaje se inscribe en una completa vacuidad de sentido, y por ello el Innombrable esta condenado a siempre recomenzar puesto que no recuerda dónde comenzó o terminó un fragmento: es como el movimiento eterno e inútil de Sísifo; Sísifo sabe por qué tiene que volver a remontar la roca a la cima del monte, y el Innombrable sabe por qué tiene que recomenzar, por que debe hablar en el intento de alguna vez encontrar su propia voz, esta voz es imposible de encontrar, es Innombrable. Así el título del texto se refiere profundamente a dos aspectos centrales del texto: por una parte se refiere a que lo que el Sujeto busca es inalcanzable, por lo tanto innombrable, por que este deseo está siempre inscrito en el Otro, por lo tanto su subjetividad será siempre diferida: «[...] he has not the remotest idea, or to Desire with a straight face the cessation of that other, equally unintelligible, assigned to him in the beginning and never modified» (376); por otra parte, lo innombrable es el texto, al cual es imposible asignarle ninguna interpretación, excepto hacer evidente problemáticas de tipo filosófico y/o psicoanalítico: se trata de un 'relato' innombrable.

Para concluir es te estudio, lo que más podemos afirmar, es que se trata solamente de unas brevísimas reflexiones sobre la escritura de Beckett y El Innombrable, son eso, reflexiones que intentan capturar una escritura y un texto que fueron escritos para no ser capturados. La reflexión sobre Beckett y su increíble producción literaria no tiene fin, como el rizoma que caracteriza toda su producción literaria: es inagotable como es innombrable.

\section{REFERENCIAS BIBLIOGRÁFICAS}

Albright, Daniel. (1981). Representation and the Imagination. Beckett, Kafka, Nobokov, and Schoenberg. Chicago and London: The University of Chicago Press.

BARTHES, Roland. (1984 [1971]). «La mort de l'auteur». En Le bruissement de la langue. Essais critiques IV, 63-69. Paris : Éditions du Seuil. (Publicado originalmente en 1971 en Manteia).

BeCKetT, Samuel. (1989). Worstward Ho. London: John Calder.

- (1955). Three Novels by Samuel Beckett: Molloy, Malone Dies, The Unnamable. New York: Wiedenfeld.

BEGAM, Richard. (1996). Samuel Beckett and the End of Modernity. Stanford, California: Stanford University Press.

— (1992). «Splitting the différance: Beckett, Derrida and The Unnamable.», 3Modern Fiction Studies 38, 4 (Winter): 873-92.

Ben-zvi, Linda. (1996). «Samuel Beckett, Frizt Mauthner y los límites del lenguaje», Beckettiana 5, 23-58.

- (1990). Women in Beckett. Performance and Critical Perspectives. Urbana and Chicago: University of Illinois Press.

— (1986). Samuel Beckett. Boston, Massachusetts: Twayne Publishers. 
Borges, Jorge Luis. (1956). Ficciones. Buenos Aires: Emecé Editores.

Boudon, Pierre. (1971). «Sobre un estatus del objeto: diferir el objeto del objeto». En Communicaciones 95-127. Buenos Aires: Editorial Tiempo Contemporáneo.

Casanova, Pascale. (2006). Samuel Beckett. Anatomy of a Literary Revolution. London - New York: Verso.

- (1997). Beckett l'abstracteur: anatomie d'une révolution littéraire Paris : Éditions du Seuil.

— (1959). «Still Novel». Yale French Studies 24: 48-53.

ConNor, Steven. (1988). Samuel Beckett. Repetition, Theory and Text. New York: Basil Blackwell.

DeArLove, J. E. (1982) Accommodating the chaos. Samuel Beckett's nonrealational art. Durham, North Carolina: Duke University Press.

Deleuze, Gilles y FÉLIX, Guattari. (1980). «Rhizome». En Mille plateaux: Captialisme et schizophrénie, 9-37. Paris : Les Éditons de Minuit.

De Toro, Fernando. (2007). «The End of Theatre Semiotics? A Symptom of an Epistemological Shift.» Semiotica, Special Issue (August ) 109-128.

- (2002). Intersecciones II. Ensayos sobre cultura y literatura en la condición postmoderna y post-colonial. Buenos Aires: Editorial Galerna.

Esselin, Martin. (1961). The Theatre of the Absurd. Garden City, New York: Anchor Books.

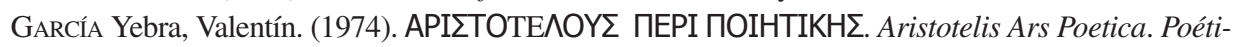
ca de Aristóteles. Edición Trilingüe. Madrid: Editorial Gredos.

Greimas, AlgiRdas Julien y Joseph Coutrés. (1979). Sémiotique. Dictionnaire raisonné de la théorie du langage. Paris : Hachette.

HABERMAS, JÛRGEN. (1998). «Modernity - An Incomplete Project». En The Anti-Aesthetic. Essays on Postmodern Culture, 1-15. Edited with and Introduction by Hal Foster. New York: The New Press.

- (1989 [1985]). The New Conservatism. Cultural Criticism and the Historian's Debate. Edited and translated by Sherry Weber Nicholsen. Introduction by Richard Wolin. Cambridge, Massachusetts: The MIT Press.

HASSAN, Ihab. (1982 [1971]). «Beckett: Imagination Ending». En The Dismemberment of Orpheus, 220-246. Madison, Wisconsin: The University of Wisconsin Press.

- (1967). The Literature of Silence. Henry Miller and Samuel Beckett. New York: Alfred a. Knopf.

IsER, Wolfgan. (1974). « Subjectivity as the Autogenous Cancellation of Its Own Manifestation.

S. Beckett: Molloy, Malone Dies, The Unnamable». En The Implied Reader. Patterns of Communication in Prose Fiction from Bunyan to Beckett, 164-178. Baltimore and London: The Johns Hopkins University Press.

HeidegGer, Martin. (1959). Unterwegs zur Sprache. Pfullingen: Neske.

HiLl, Leslie.(1990). Beckett's Fiction in Different Words. New York, Port Chester, Melbourne, Sydney: Cambridge University Press.

Janviet, Ludovic. (1966). Pour Beckett. Paris: Les Éditions de Minuit.

JAUSS, Hans-roberet. (1977). Aesthetische Erfahrung and literarische Hermeneutik I. München: Wilhelm Fink Verlag.

JenKC, Charles. (1989). What is Post-Modernism? Third Edition. New York: St. Martin' Press. KRYSINSKI, Wladimir. (1998). La novella y sus modernidades. A favor y encontra de Bajtin. Frankfurt am Main: Vervuert Verlag.

Kunn, Thomas. (1970). The Structure of Scientific Revolutions. Second Edition, Enlarged. Chicago: University of Chicago Press. 
LACAN, Jacques. (1973). Les quatre concepts fondamentaux de la psychanalyse. Le séminaire de Jacques Lacan, Livre XI. Paris : Éditions du Seuil.

Mchale, Brian. (1987). Postmodernist Fiction. New York and London: Methuen.

Moles, Abraham. (1971). «Objeto y Comunicación». En Communicaciones? 9-35. Buenos Aires: Editorial Tiempo Contemporáneo.

- (1975). Teoría de los objetos. Barcelona: Gustavo Gili.

PheBy, Keith C. (1988). Interventions. Displacing the Metaphysical Subject. Washington, D.C.: Maisonneuve Press.

RoA Bastos, augusto. (1974). Yo el Supremo. México: Siglo XXI Editores

RobBe-Grillet, Alain. (1963). Pour une nouveau roman. Paris: Les Éditons de Minuit.

TrezISE, Thomas. (1990). Into the Breach: Samuel Beckett and the Ends of Literature. Princeton: Princeton University Press.

Uhlmann, Anthony. (1999). Beckett and Poststructuralism. Cambridge, United Kingdom: Cambridge University Press.

VALENTI, Jean. (2006). « Alterité et situation cognitive : L'innommable de Samuel Beckett». En L'autre en mémoire. Dominique Laporte, Editor. Québec: Les Presses de l'université Laval, pp. 199-224.

VAtTimo, Gianni. (1985). La fine della modernità. Italia: Grazanti Editore.

WeISBERG, David. (2000). Chronicles of Disorder. Samuel Beckett and the Cultural Politics of the Modern Novel. Albany, New York: State University of New York Press.

WittgensteIn, Ludwig. (1961). Logish-Philosophische Abhandlung. New York: Routledge and Keang Paul.

— (1921). «Logish-Philosophische Abhandlung». Annalen der Naturphilosophie. Vierzehnter Band, mit 12 Figuren im Text: 185-262. 
